\title{
La responsabilidad social empresarial: ¿verda- dero compromiso o simple moda?
}

\author{
LUIS FELIPE CAMPUZANO*
}

SUMARIO: INTRODUCCIÓN.- I. VOLUNTARIEDAD.- II. DECISIÓN DE LAS
EMPRESAS.- III. PREOCUPACIONES SOCIALES Y MEDIOAMBIENTALES.-
IV. OPERACIONES COMERCIALES Y RELACIONES CON INTERLOCUTORES.-
V. LA RSE NO ES MARKETING SOCIAL.- VI. LA RSE NO ES ACCIÓN SOCIAL
PUNTUAL O FILANTROPÍA.- VII. LA RSE NO ES CUMPLIMIENTO DE LA LEY.

\section{NTRODUCCIÓN}

En estos tiempos difíciles, cualquiera que siga de cerca el devenir de las grandes corporaciones, fundamentalmente las cotizadas, podrá constatar el tremendo auge que está adquiriendo un «nuevo» fenómeno al que se ha dado en llamar responsabilidad social empresarial (RSE).

Y entrecomillamos el adjetivo «nuevo» porque, aunque la eclosión de la RSE es relativamente reciente, su formulación arranca décadas atrás, posiblemente tras los horrores derivados de la Guerra de Vietnam y otros conflictos como el apartheid sudafricano.

Se trata de un fenómeno surgido bajo el impulso de distintas iniciativas internacionales: Declaración de la OCDE sobre inversiones internacionales y empresas multinacionales, Declaración Tripartita de Principios sobre las Empresas Multinacionales y la Política Social de la OIT, Pacto Mundial de Naciones Unidas, Libro Verde de la Comisión Europea, Global Reporting Initiatives...

Pero, como decíamos, es ahora cuando el fenómeno va adquiriendo un auge considerable, casi abrumador. Centrándonos en España, un reciente estudio llevado a cabo por el Club de Excelencia en Sostenibilidad sobre 121 compañías de gran tamaño pone de relieve que el 71\% de estas cuenta con una estrategia determinada para implementar y desarrollar principios de RSE, y que el 100\% tiene en cuenta, además, las expectativas de distintos grupos de interés (fundamentalmente empleados, clientes y proveedores) al elaborar sus planes en esta materia.

Siguiendo en España, el último informe presentado por la Red Española del Pacto Mundial develaba que el número de firmantes de los compromisos establecidos en dicha iniciativa auspiciada por Kofi Annan, en 1999, y promovida desde Naciones Unidas crece anualmente a tasas superiores al 20\%. Y así, podríamos continuar con los ejemplos 
y extendernos hasta el infinito, y aburrir al lector con estadísticas que proporcionan a la postre datos semejantes.

De buenas a primeras, todo un universo de conceptos novedosos y biensonantes ha irrumpido para apoderarse del argot empresarial. Expresiones como «informes de sostenibilidad», «códigos de conducta», «triple cuenta de resultados», «inversiones socialmente responsables», etcétera, etcétera, comienzan a ser cada vez más habituales en el mundo de los negocios. Expresiones que, dicho sea de paso, no pretenden sino diferenciar un modo de gestionar que se presenta ante la sociedad con los adjetivos de «ético» $\mathrm{y}$ «responsable».

Ahora bien, artificios retóricos aparte, ide qué diantres estamos hablando cuando nos referimos a la responsabilidad social empresarial como sinónimo de novedoso estilo de gestión? ¿Acaso no es ya suficientemente responsable el empresario por el mero hecho de iniciar una aventura que implica exponer su patrimonio personal con el fin de generar riqueza y, por ende, puestos de trabajo? ¿Tal vez no basta con el estricto control fiscal, laboral y contable al que todo emprendedor ha de enfrentarse en el día a día de su actividad, como para tener que atosigarlo ahora con nuevas obligaciones? ¿Es que, quizá, no es ya más que suficiente tener que competir en precios, márgenes, calidad, innovación y políticas comerciales, en entornos cada vez más globales y cambiantes, y a pesar de todo ello ser capaces de lograr eficiencia y eficacia?

Pues no. Definitivamente la respuesta a todas estas interrogantes es un «no» rotundo. A lo largo de estas líneas, trataremos de explicar por qué.

Cualquier compañía, independientemente de su tamaño, sea cual sea el sector en el que compita y al margen de su posición estratégica, no es sino una pieza más de un engranaje. Un complejo mecanismo formado por muchos otros componentes que, al unirse e interactuar, consiguen entre todos arrancar y poner en marcha un motor. Un motor que no es otro que el de la propia sociedad dentro de la que se desenvuelven. Del mismo modo en que la mejor de las bujías resultaría ineficaz instalada en un motor herrumbroso, oxidado, la mejor de las empresas estaría avocada al fracaso instalada dentro de una sociedad enferma y sin futuro previsible.

Las empresas que aspiren a mantener su viabilidad en el medio y largo plazo no pueden ser ajenas a lo que nos depara el futuro; no pueden desentenderse de su entorno social y vivir de espaldas a él. En definitiva, no pueden pretender funcionar como entes introvertidos y aislados. Por el contrario, al igual que otros muchos colectivos, organizaciones y entidades con los que conviven e interactúan, también las empresas deben aportar su grano de arena en la consecución de un desarrollo sostenible basado en el bienestar social y el crecimiento económico. 
Ya nadie duda de que nos encontramos en pleno tránsito entre el Estado del Bienestar y la Sociedad del Bienestar. O lo que es lo mismo: ya nadie aspira a que sea el Estado quien ostente el monopolio de la consecución del bienestar común; entre otras razones, porque los recursos del Estado son limitados y para acrecentarlos no le queda otra opción que recurrir a la presión fiscal.

Junto al Estado deben alinearse, pues, para «tirar del carro», organizaciones de todo tipo (empresariales, sindicales, religiosas, cívicas, ONG...). Y, por supuesto, junto al Estado deben alinearse las empresas. No olvidemos que hoy en día, en el ranking de los cien mayores ratios económicos mundiales, aparecen cerca de cuarenta empresas que compiten con muchos países, e incluso los superan en tamaño.

Ahora bien, siendo honestos, tampoco debemos soslayar el elemento clave implícito en la definición de empresa. Cualquier empresa no es sino un ente encaminado hacia la administración eficiente de sus recursos y la optimización de su cuenta de resultados. Como tal, está obligada a maximizar sus beneficios y rendir cuentas ante sus accionistas.

Por lo tanto, habría que reflexionar a renglón seguido sobre la incidencia que pueda llegar a tener contra la cuenta de resultados el hecho de contribuir al bienestar común al adoptar criterios de RSE en su gestión, lo que implica automáticamente detraer recursos para ello. O lo que es lo mismo: habría que analizar si realmente la sociedad está teniendo en cuenta este sobreesfuerzo empresarial al consumir o invertir. Porque, siendo realistas, si el mercado no premia de modo alguno tales prácticas, el futuro de la RSE estará en entredicho.

Afortunadamente, esta incógnita parece estar resuelta y ya es de dominio público que las iniciativas de RSE suponen una inversión y no un gasto. Los ciudadanos comienzan a percibir que, comprando los productos o servicios de determinadas empresas o canalizando sus inversiones hacia ellas, también contribuyen al bien común. Así lo demuestra el creciente auge de opciones como el comercio justo, las inversiones verdes, la banca ética o los fondos solidarios.

Poco a poco, gracias a la información, se van imponiendo y generalizando el consumo y la inversión socialmente responsables. Y de ahí deriva el hecho de que una empresa socialmente responsable pueda llegar a ser mucho más competitiva gracias a la reputación obtenida con su modo de actuar. Además, parece estar demostrado que el rendimiento medio de los empleados de empresas con altos niveles de responsabilidad supera con creces al de otras corporaciones menos concienciadas.

El Informe Forética sobre la evolución de la RSE en España señala que nueve de cada diez ciudadanos rechazan abiertamente las prácticas irresponsables de las empresas y estarían dispuestos a penalizar el consumo de sus productos si llegaran a tener conocimiento de estas. Entre dos 
productos similares, el consumidor medio optaría por el de una empresa socialmente responsable. Incluso, según nos desvela el referido informe, uno de cada dos españoles, basado en motivaciones éticas, ha dejado alguna vez de consumir algún producto.

En cualquier caso, es bueno tener en cuenta que, a priori, al empresario se le plantea un posible conflicto de intereses que resulta necesario armonizar. La RSE debe buscar el equilibrio entre los intereses de los integrantes directos de la empresa (accionistas, directivos y trabajadores) y los de otros grupos que integran el entorno social en el que la empresa se desenvuelve, y que resultan concernidos por su actividad (proveedores, clientes, comunidad en general).

Sentadas estas premisas, y dando por hecho que la RSE no es una moda pasajera y ha venido para quedarse, podemos pasar a definirla. Para ello, entre las cientos de definiciones disponibles, nos apoyaremos en la de la Comisión Europea, que la ha tratado de explicar lacónicamente con las siguientes palabras: «La Responsabilidad Social Empresarial es la integración voluntaria por parte de las empresas de una serie de preocupaciones sociales y medioambientales en sus operaciones comerciales y en las relaciones con sus interlocutores». A partir de esta definición podemos resaltar los siguientes puntos.

\section{VOLUNTARIEDAD}

Este aspecto es crucial al entender la auténtica responsabilidad social. La estricta observancia de lo que es obligatorio está fuera de toda discusión y, por lo tanto, no puede ser calificada de «responsable». La responsabilidad social va mucho mas allá: supone un plus sobre lo que ya establece la ley. Incorporarla o no incorporarla es una libre opción del empresario.

Ahora bien, ninguna empresa que cumpla taxativamente la legislación vigente en materia social, medioambiental y laboral debería ser discriminada al acceder a subvenciones o ayudas públicas por el hecho de no incorporar, a su vez, iniciativas de «responsabilidad social». Lamentablemente, no existe unanimidad al respecto y son muchas las voces que claman por la imposición obligatoria de este tipo de iniciativas.

El origen de esta reivindicación hay que buscarlo quizás en esta última crisis económica en la que estamos inmersos y que ha venido propiciada, en cierta medida, por determinados comportamientos irresponsables. Por ello, no estaría de más, sin olvidarnos de la voluntariedad, elevar el listón regulador para evitar situaciones semejantes futuras que puedan poner en peligro el sistema global.

Sin llegar, en caso alguno, a proponer la obligatoriedad, estamos de acuerdo en que hay que exigir mayor transparencia y garantías efectivas a fin de que los códigos de conducta no se conviertan en simples elementos de marketing. 


\section{DECISIÓN DE LAS EMPRESAS}

La definición de RSE que nos da la Comisión Europea recoge textualmente la frase «por parte de las empresas». Este es uno de los aspectos más controvertidos que rodean a la responsabilidad social. ¿Quién, en el seno de la empresa, debe tomar la decisión de implementar modelos de gestión socialmente responsables? ¿Corresponde la decisión al consejo de administración? ¿Tal vez a los directivos? ¿Deberían estar implicados los trabajadores en la toma de este tipo de decisiones?

A nuestro juicio, un acertado modelo de responsabilidad social es aquel que impregna de tal modo a la organización, a sus procedimientos y procesos que acaba siendo proyectado centrífugamente hacia todos los grupos de interés (stakeholders) con los que esta se relaciona.

Y ningún grupo de interés tiene mayor relevancia para una empresa que sus propios trabajadores. La RSE debe empezar, pues, puertas adentro. Resulta muy difícil, casi imposible, catalogar como socialmente responsable a una empresa que no aplique una buena política de personal.

Por este motivo, toda compañía, al apostar por un modelo de tanta trascendencia como el que nos ocupa, debería involucrar en la decisión, desde el minuto cero, al colectivo de trabajadores que conforman su plantilla a través de sus representantes legales.

Si realmente pretendemos que la RSE llegue a formar parte de la estrategia al integrarse en la gestión y constituirse en un elemento transversal que implique a todos los niveles de la empresa, hay que contar, ineludiblemente, con la opinión de los trabajadores a la hora de formular las iniciativas.

Posiblemente esta sea una de las asignaturas pendientes en los actuales modelos de RSE y de ello derive la presente desconfianza que todavía muestran algunos sindicatos hacia estos.

\section{PREOCUPACIONES SOCIALES Y MEDIOAMBIENTALES} El fenómeno de la deslocalización ligado al de la globalidad han propiciado que muchas compañías transnacionales hayan establecido sus operaciones en países del tercer mundo. Estas buscan ventajas competitivas e ignoran, en algunos casos, los más elementales derechos sociales y laborales.

A todos nos vienen a la mente ejemplos de denuncias muy sonadas que, basadas en estos incumplimientos, han causado un importante desgaste en la reputación de compañías de mucho renombre.

En un intento de contrarrestar este tipo de amenazas y ofrecer una cara algo mas amable de las empresas, la responsabilidad social ha tratado, desde sus orígenes, de incidir sobre los grandes problemas sociales que aquejan a la humanidad (el hambre, la educación, la sanidad, la pobreza 
en general...). A ello se añade, más recientemente, la preocupación derivada de los efectos perversos provocados por el cambio climático y el exceso de emisiones de gases de efecto invernadero. Esto ha hecho desplazar el foco de interés y ha motivado la aparición de muchas y muy loables iniciativas de RSE en el ámbito medioambiental.

Pero ha sido en los dos últimos años, a consecuencia de la crisis económica que estamos padeciendo, cuando ha irrumpido con fuerza un tercer problema: nos referimos al desempleo. La desaceleración golpea con tal crueldad al sistema que, ante la falta de liquidez y la dificultad de acceso a los mercados financieros, son miles las empresas que se han visto abocadas cerrar definitivamente, lo cual ha generado una imparable espiral de destrucción de empleo.

Tan solo en España, según datos del Instituto Nacional de Estadística, el ratio de desocupación afecta ya a cerca del $20 \%$ de la población activa, y las perspectivas para los próximos años no son nada halagüeñas. Esto ha hecho que, en el barómetro que acaba de publicar el Centro de Investigaciones Sociológicas (CIS), el paro aparezca como la principal preocupación para el 78,4\% de los ciudadanos, hecho que ha desbancado de la cúspide del ranking a la lacra del terrorismo.

Como efecto positivo, si es que cabe hablar de positivismo en semejantes tesituras, cabe constatar que son muchas las empresas que han visto en el «empleo» un nuevo eje de actuación para las iniciativas de RSE y han comenzado a destinar parte de sus esfuerzos a acciones que conllevan una mejora de la calidad del empleo y un enriquecimiento de los derechos laborales reconocidos tanto por la legislación vigente como por la negociación colectiva.

\section{IV.OPERACIONES COMERCIALES Y RELACIONES CON INTERLOCUTORES}

Como acabamos de ver, la Comisión Europea se refiere expresamente en su definición a «las operaciones comerciales y a las relaciones con los interlocutores». Y es aquí donde, posiblemente, radique la esencia de la RSE como elemento totalmente alejado del marketing social: ir más allá del entorno inmediato, tener amplitud de miras, extenderse a todo tipo de interlocutores y grupos de interés, e incluir, por supuesto, al entorno social y medioambiental en el que una empresa se desenvuelve.

El ámbito de la RSE trasciende del ámbito de la propia empresa para abarcar a todos aquellos colectivos que, de cualquier manera, puedan llegar a verse concernidos por la actividad que ella desarrolla. Es necesario alcanzar un equilibrio sostenible entre el objetivo por antonomasia de cualquier empresario — el de maximizar el valor de su compañía- y otros objetivos sociales y medioambientales que, sin trascender de manera inmediata sobre la cuenta de resultados, pueden llegar a ser altamente beneficiosos en términos de imagen y reputación. 
La RSE, pues, desborda los límites en los que se enmarcan los grupos cuyo interés es estrictamente económico (stockholders) para alcanzar a aquellos otros que demuestran un interés social o de otro tipo (stakeholders). La lista de stakeholders que pueden verse afectados por la actividad de la empresa puede llegar a ser tremendamente amplia (inversionistas, empleados, familiares, clientes, proveedores, sindicatos, administraciones, universidades, comunidad...). Es misión de la empresa identificarlos correctamente a fin de minimizar los impactos negativos sobre ellos y potenciar, en consecuencia, los positivos.

Y hasta aquí el análisis de la definición de RSE de la Comisión Europea, pero, al margen de ella, también podemos encontrar algunos rasgos definitorios de lo que no es la RSE que nos van a ser tremendamente útiles para entender y enmarcar este fenómeno.

\section{LA RSE NO ES MARKETING SOCIAL}

Todavía son muchos quienes piensan que la RSE no es sino una herramienta sofisticada del marketing mix destinada a lavar la imagen de la empresa y posicionarla del modo más amable posible ante la sociedad, con el fin de obtener réditos a corto plazo. Una variante del marketing a la que denominan, de forma quizá un tanto rebuscada, marketing social o marketing con causa.

Pero el marketing, como componente de la estrategia empresarial, se basa en una relación directa proveedor-cliente que deja fuera de su campo de acción a otros posibles stakeholders. El marketing es, en definitiva, cortoplacista y busca directamente y sin ambages el incremento de las ventas, la mejora de la imagen de marca frente a competidores y el posicionamiento social. Se actúa por interés, no por altruismo.

Es verdad que son muchas las compañías que han vendido como iniciativas de RSE lo que no son sino meras estrategias propagandísticas destinadas a incitar al consumo de sus productos, incrementar el reconocimiento de sus marcas y acceder a nuevos segmentos de mercado. Pero seamos claros: eso no es RSE.

La auténtica RSE no es cortoplacista y va mucho mas allá del beneficio inmediato; implica un cambio cultural pleno que impregna de forma transversal a la empresa, a sus procedimientos y procesos, a sus trabajadores y directivos, a sus sistemas de información... Se extiende, en última instancia, como ya hemos explicado, a todos los grupos de interés, directos e indirectos, con los que la empresa se relaciona. presas con actividades de interés general situadas fuera de la zona de 
influencia de su actividad productiva o comercializadora, también se distingue, y mucho, de la RSE.

Sin poner en tela de juicio este tipo de comportamientos, que por supuesto contribuyen al bien común y al interés general, no podemos obviar su carácter puntual. $\mathrm{O}$ dicho de un modo sencillo: se trata de iniciativas que pueden producirse en un año concreto y desaparecer automáticamente al siguiente, en virtud de cómo evolucionen los resultados de la compañía y su capacidad para detraer recursos para acción social. En definitiva, la empresa modula su compromiso en función del momento y de las circunstancias.

Hablamos de colaboraciones empresariales muy loables que pueden ser directas o a través de entidades no lucrativas que son las que, en última instancia, canalizan e invierten los recursos sin que la empresa que los aporta se involucre directamente en el proyecto. Se trata de aportaciones que, a su vez, pueden manifestarse en distintas formas: dinero, especie o incluso cesión temporal de recursos humanos.

La RSE, por el contrario, no es puntual en función de la coyuntura, sino estructural. El compromiso que conlleva es duradero.

\section{LA RSE NO ES CUMPLIMIENTO DE LA LEY}

Ya lo hemos apuntado con anterioridad, pero no nos cuesta repetirlo: un comportamiento socialmente responsable implica ir más allá de lo que determina la normativa legal y el resultado de la negociación colectiva. Supone un plus sobre lo obligatorio. Es una decisión voluntaria de la empresa.

El cumplimiento de las normas es algo que se da por supuesto y que la empresa acata como condición sine qua non para el desarrollo de su actividad. La legislación laboral y la normativa medioambiental marcan el punto de partida. Solamente a partir de su estricto cumplimiento puede comenzar a levantarse el edificio de la RSE y elevar los mínimos legales en una relación de suplementariedad.

Y es aquí donde surge el matiz derivado de ciertas practicas de RSE que nacen a partir de la consideración de las empresas hacia sus grupos de interés pero acaban materializándose en pactos, acuerdos o convenios; alcanzan carácter normativo y tornan difícil, de cara al futuro, seguir siendo consideradas como RSE.

Otro matiz a tener en cuenta radica en la diversidad de los ordenamientos jurídicos de los países. Sobre la base de dicha diversidad, comportamientos que son obligatorios en unos no pasan de ser voluntarios en otros, con la consiguiente dificultad de su clasificación o no dentro del ámbito de la RSE. 
Pero matices aparte, lo que realmente nos debe preocupar en este deslinde del concepto de RSE es la predisposición del empresario a ofrecer un plus sobre lo exigible y, como resultado, la integración en la cultura de la empresa de las iniciativas surgidas de dicha predisposición hasta el punto de llegar a proyectarse hacia todos los grupos de interés con los que la empresa se relaciona.

Es verdad que no son pocas las empresas que, al elaborar sus memorias de sostenibilidad, tratan de presentar como RSE lo que no es sino puro cumplimiento de la norma, pero el engaño ya no cuela. La sociedad, bien informada, ya no lo permite.

Aspiramos humildemente a que las consideraciones expuestas hayan sido útiles para situar el concepto de RSE y diferenciarlo de posibles sucedáneos. Terminamos este artículo con la reflexión que hacíamos al principio: RSE, iverdadero compromiso o simple moda?

Puesto que todos conocemos múltiples iniciativas de RSE desarrolladas por grandes empresas en nuestros respectivos entornos geográficos, y teniendo en cuenta las cautelas reseñadas, dejamos a la consideración del lector la respuesta al interrogante. 